\title{
Seasonality of Lutzomyia fairtigi (Diptera: Psychodidae: Phlebotominae), a species endemic to Eastern Colombia
}

\author{
Jorge Alberto Molina/ ${ }^{+}$, Mario Iván Ortiz, Felipe Guhl \\ Centro de Investigaciones en Microbiologia y Parasitologia Tropical, Universidad de Los Andes, Departamento de Ciencias Biológicas, \\ Apartado Aéreo 4976, Bogotá, Colombia
}

The bionomics of sand flies (Diptera: Phlebotominae) was studied monthly for two consecutive years in alluvial gallery forests in the department of Casanare, Northeastern Colombia. A total of 2,365 specimens and 10 species were captured using CDC light traps and Shannon traps, and from diurnal resting places, and human landing collections. Lutzomyia fairtigi Martins (55\%), Lutzomyia micropyga (Mangabeira) (20.9\%), and Lutzomyia antunesi (Coutinho) (13.5\%) were the predominant species in the region. Lutzomyia flaviscutellata and Lutzomyia panamensis, potential vectors of Leishmania in Colombia and neighboring countries, were also collected, but in low numbers. Lu. fairtigi is an endemic species to Colombia, and minimal data are available on its biology and distribution. The present study provides additional information about $\mathrm{Lu}$. fairtigi, such as the diurnal activity displayed by females on cloudy days, the greater density during the rainy season (April to October), marked anthropophilia, and the presence of flagellates in the midgut of one female.

Key words: Phlebotominae - Lutzomyia fairtigi - Colombia - leishmaniasis - sand flies

Phlebotomine sand flies are the vectors of leishmaniasis and phleboviruses, both of which cause important health problems and diseases in humans and domestic animals (Alexander 2000). In Colombia, 141 species of Phlebotomine sand flies have been reported (Bejarano 2007), and 27 of them are endemic to Colombia. Most of the endemic species have been reported with very little data, such as a first description of the species and preliminary geographic distribution. Consequently, additional important epidemiological information is lacking for most of these species. The only Psychodopygus species endemic to Colombia is Lutzomyia fairtigi Martins (Williams 1999). Lu. fairtigi was collected and described for the first time in forests close to Villavicencio (department of Meta, ME) using light and Shannon traps (Martins 1970). Bejarano (2007) showed that the geographical distribution of $L u$. fairtigi is restricted to the eastern part of Colombia, in the departments of Caquetá, Casanare (CA), $\mathrm{ME}$ and Vaupés (Fig. 1). However, no information related to its epidemiological status has been reported (Young \& Duncan 1994) with regard to natural Leishmania parasite infections and/or feeding habits.

Leishmaniasis is an endemic disease in Colombia (except in San Andrés, Atlántico and Bogotá) (Corredor et al. 1990). In 2007, 5,771 cases were reported $(97.7 \%$ cutaneous, $1.39 \%$ mucocutaneous, and $0.9 \%$ visceral) (SIVIGILA; www.ins.gov.co/nivel3. php?seccion=26\&sub=45). The Leishmania species isolated from humans, animals, and sand flies were $L$. (Viannia) panamensis $(53.8 \%)$, L. (Viannia) brazilien-

+ Corresponding author: jmolina@uniandes.edu.co

Received 8 March 2008

Accepted 21 July 2008 sis (30.3\%), L. (Leishmania) infantum (9.4\%), L. (Viannia) guyanensis (2.6\%), L. (Leishmania) amazonensis $(1.8 \%)$, and L. (Leishmania) mexicana $(0.8 \%)$ (Corredor et al. 1990). More recently, similar results were obtained from patients arriving in Bogotá from different regions of Colombia: L. panamensis $(74.45 \%)$, L. braziliensis (15.33\%), L. guyanensis $(0.73 \%)$, L. mexicana $(5.11 \%)$, and L. mexicana complex (3.65\%) (Ovalle et al. 2006). In the departments of Caquetá, CA, ME and Vaupés, a total of 31,282 cases of leishmaniasis have been reported since 2000 (99.7\% were cutaneous, 0.24\% mucocutaneous, and $0.03 \%$ visceral) (SIVIGILA). The parasite species circulating in these four departments were L. panamensis, L. braziliensis, L. amazonensis, L. guyanensis, and L. mexicana (Corredor et al. 1990, Ovalle et al. 2006). In the same departments, 66 species of Lutzomyia were reported, six of which are vectors of Leishmania in Colombia (Bejarano 2007).

To improve our knowledge of leishmaniasis transmission in CA, two consecutive years of entomological surveillance were carried out in this department. The main objectives of the survey were to determine monthly and annual trends in the species composition, monthly densities, and infection rates of sand flies.

\section{MATERIALS AND METHODS}

Study area - Sand flies were collected in Tauramena Municipality, CA $\left(5^{\circ} 00^{\prime} \mathrm{N}, 72^{\circ} 42^{\prime} \mathrm{W}\right)$ in the Eastern Cordillera of the Colombian Andes (Fig. 1). The region is described as tropical premontane wet forest with some elements of tropical wet forest (IGAC 1988) located approximately $450 \mathrm{~m}$ above sea level. On average, the annual rainfall is $2,842 \mathrm{~mm}$, mainly occurring between April and October. The annual temperatures range from a minimum of $18^{\circ} \mathrm{C}$ to a maximum of $34^{\circ} \mathrm{C}$, with an average of $25.5^{\circ} \mathrm{C}$, and the relative humidity ranges from $76 \%$ to $84 \%$, with an average of $81 \%$ (Fig. 2 ). 


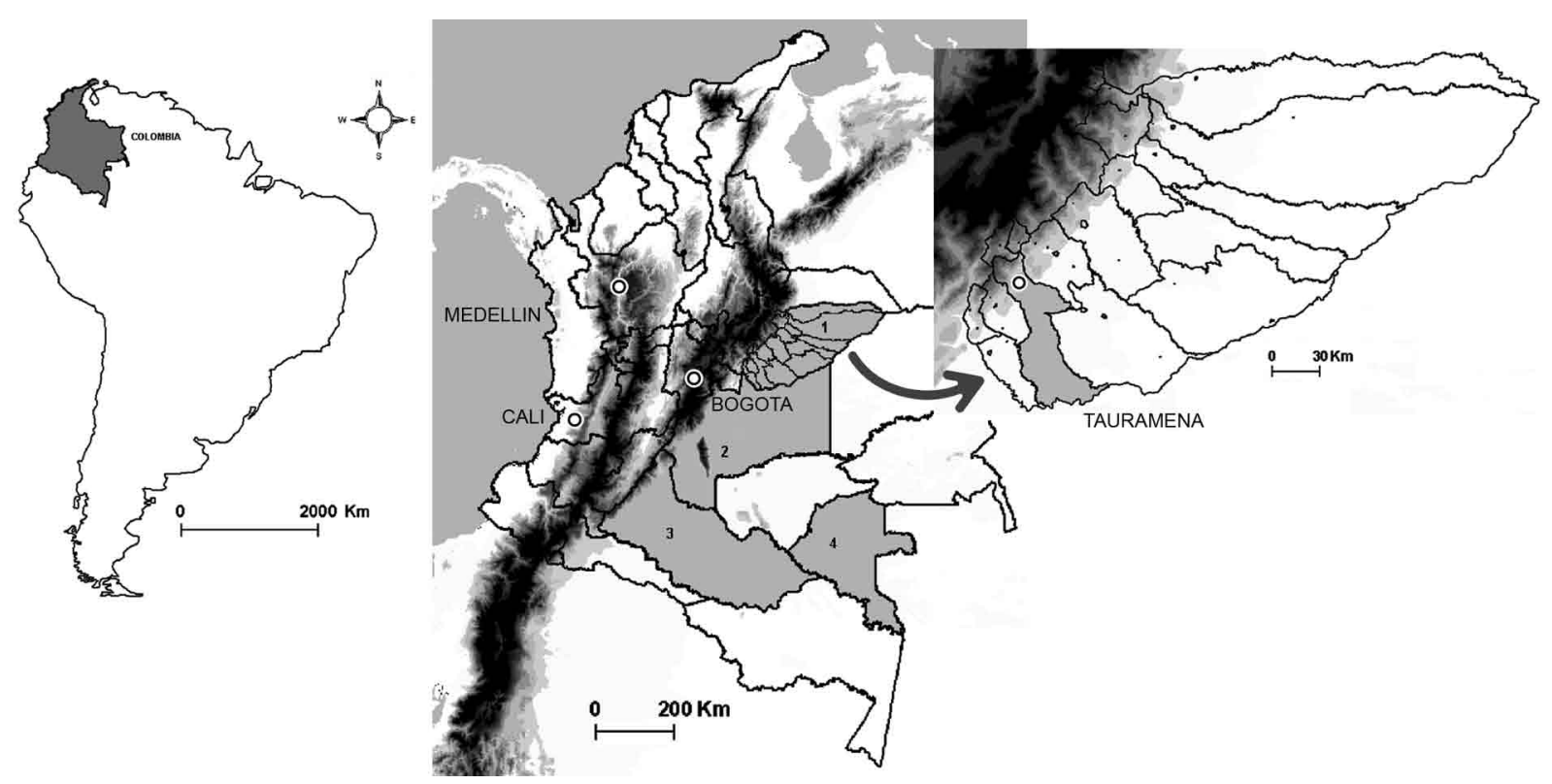

Fig. 1: geographical position of Colombia and national departments with Lutzomyia fairtigi reports. 1: Casanare; 2: Meta; 3: Caquetá; 4: Vaupés. Some cities are also shown: Cali (West), Medellín (North) and Bogotá (Center). Right: departmet of Casanare and location of Tauramena Municipality (gray), where the study area is mark with a dot.

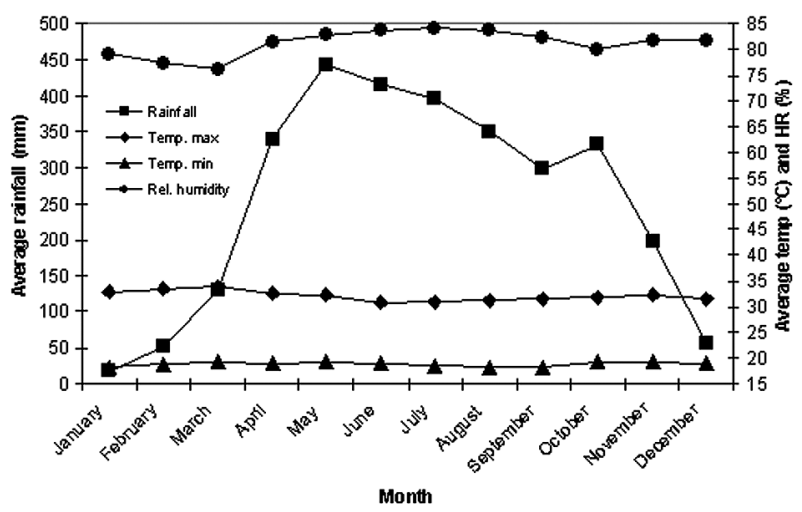

Fig. 2: average climatic conditions in Tauramena municipality in the past 20 years (January 1987 - December 2007). Data from the Tauramena station number 3519502, of Instituto de Hidrología, Meteorología y Estudios Ambientales, Colombia.

Capture sites and sand fly collection and identification - Sand fly collections were carried out in three patches of forest (patch A: $4^{\circ} 59^{\prime} 54.3^{\prime \prime} \mathrm{N}, 72^{\circ} 42^{\prime} 39.6^{\prime \prime} \mathrm{W}$; patch B: $5^{\circ} 00^{\prime} 59.9^{\prime \prime} \mathrm{N}, 72^{\circ} 42^{\prime} 54.3^{\prime \prime} \mathrm{W}$, and patch C: $5^{\circ} 00^{\prime} 46.8^{\prime \prime} \mathrm{N}, 72^{\circ} 42^{\prime} 46.4^{\prime \prime} \mathrm{W}$ ) bordering small rivers. These alluvial gallery forests are a common element of the tropical grassland savannas (Llanos Orientales) in Colombia. The sand flies were collected during two periods of two consecutive years, with monthly collections of three nights from March 1996 to February 1997 and August 1997 to July 1998. To investigate the geographical distribution, activity, seasonality, and anthropophilic habits of the species, different methods of capture were used (Alexander 2000). The collections were performed by: (i) aspiration of sand flies from tree trunks and but- tress roots to investigate diurnal resting places by one collector for about $5 \mathrm{~min}$ per tree, with a total of 250 and 222 trees included in the survey during the 1st and 2nd years, respectively; (ii) disturbing those sand flies resting on leaf litter during the day with a mesh-covered wooden frame containing a triangular cross-section with an area of $0.3 \mathrm{~m}^{2}$, an area of $9 \mathrm{~m}^{2} /$ month was covered during the first year (this technique was not used in the 2nd year); (iii) using CDC miniature light traps suspended approximately $2 \mathrm{~m}$ above the ground each night, with two traps/night set $1 \mathrm{~h}$ before sunset and collections performed after sunrise the next morning; (iv) using one Shannon trap between 18:30 $\mathrm{h}$ and 20:30 h each night; (v) human landing collection of insects attracted to arms exposed by one collector during the Shannon trap sampling time (i.e., between 18:30 $\mathrm{h}$ and 20:30 h); and (vi) human landing collections during daylight hours, while aspiration of sand flies from tree trunks and leaf litter were carried out.

All sand flies were preserved in $70 \%$ alcohol for transportation to Centro de Investigaciones en Microbiología y Parasitología Tropical, where they were cleared in lactophenol, prepared and identified to species (Young $\&$ Duncan 1994).

Sand fly cryopreservation - Sand flies collected between August 1997 and January 1998 were cryopreserved in liquid nitrogen and later dissected in sterile PBS ( $\mathrm{pH}$ 7.4) under a compound microscope according to standard methodology (Young et al. 1987). Midgut, hindgut, and Malpighian tubules were examined in order to detect flagellates. The presence, location, and intensity of flagellates were noted, as well as whether they were alive and active (Minter \& Goedbloed 1971). Attempts to culture sandfly flagellates were made using NNN media (Minter \& Goedbloed 1971, Young et al. 1987). 
Data analysis - The correlation between the number of sand flies captured and the year of sampling was analyzed using Spearman's rank correlation test (Zar 1999). SPSS software was used to perform linear regressions between the average monthly number of sand flies captured using all sampling methods during the two years and the following environmental variables: precipitation, maximum temperatures, and relative humidity. Percentage values of relative humidity were used after angular transformation (Zar 1999).

\section{RESULTS}

A total of 2,365 sand flies (845 males and 1,520 females) from two different groups, five subgenera, and 10 different species were collected (Table I). Lu. fairtigi represented the species with the highest number of individuals captured during both years $(55 \%)$, followed by Lutzomyia micropyga (Mangabeira) (20.9\%) and Lutzomyia antunesi (Coutinho) (13.5\%). Lu. fairtigi was not only abundant in the alluvial gallery forests of CA, but was also found to be an anthropophilic species, with individuals captured during human landing collections at night, as well as cloudy days (around 9:00 $\mathrm{h}$ and 16:0017:30 h). Lu. micropyga was captured exclusively at tree buttresses used as diurnal resting sites. Collections on leaf litter covered approximately $108 \mathrm{~m}^{2}$, and resulted in 15 sand flies of five species (Table I), with an average yearly density of one sand fly per $7 \mathrm{~m}^{2}$. Lu. fairtigi, Lu. antunesi, and Lutzomyia panamensis (Shannon) were the most frequently collected species when using CDC and Shannon light traps (Table I).

A seasonal fluctuation in the density of $L u$. fairtigi was found to be correlated with the average monthly rainfall, maximum temperature, and relative humidity (Table II). The same analysis for $L u$. micropyga and $L u$. antunesi did not demonstrate a correlation between sand fly densities and environmental variables (Table II). However, the mean monthly numbers of Lu. micropyga collected increased during the rainy months from April

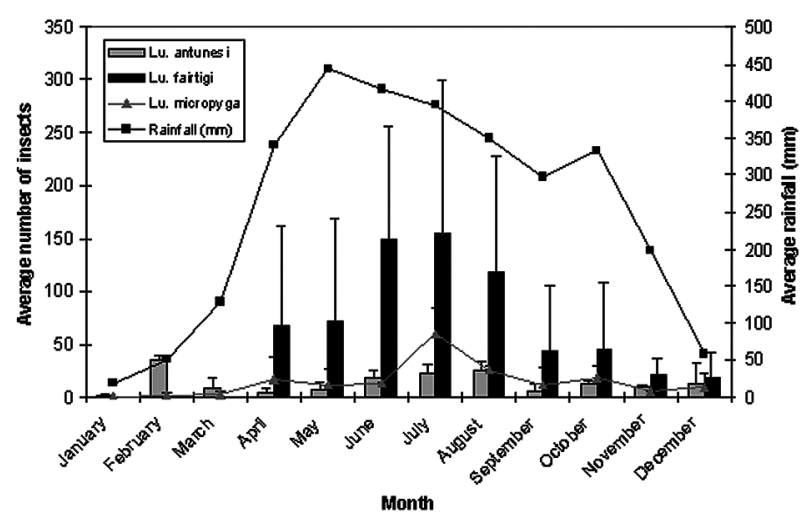

Fig. 3: monthly average numbers of the three most frequent Lutzomyia sand flies (with standard deviation) captured in the two years [March 1996 to February 1997 (1st year) and August 1997 to July 1998 (2nd year)] and monthly average rainfall reported in Tauramena Municipality, department of Casanare, Colombia, during the past 20 years (1987-2007). to October. The same trend was observed for Lu. fairtigi, which disappeared during the months without rainfall (January to March), while Lu. micropyga and Lu. antunesi were present throughout the year (Fig. 3). A multiple linear regression between the three most abundant species and the environmental variables (rainfall, maximum temperature, and relative humidity) showed a significant correlation for $\mathrm{Lu}$. fairtigi $\left(\mathrm{R}^{2}=0.796, \mathrm{~F}=10.38\right.$ and $\mathrm{p}=0.004)$. In the cases of Lu. antunesi and $L u$. micropyga, no significant correlations with environmental variables were found $\left(\mathrm{R}^{2}=0.104, \mathrm{~F}=0.31, \mathrm{p}=0.818\right.$; $\mathrm{R}^{2}=0.441, \mathrm{~F}=2.106, \mathrm{p}=0.178$, respectively).

Sand flies representing eight Lutzomyia species were dissected: $L u$. antunesi, $L u$. damascenoi (Mangabeira), Lu. fairtigi, Lu. flaviscutellata (Mangabeira), Lu. micropyga, Lu. panamensis, Lu. punctigeniculata (Floch \& Abonnenc), and $\mathrm{Lu}$. walkeri (Newstead). A total of 328 females were examined for natural infection with flagellate forms, but only one out of $259 \mathrm{Lu}$. fairtigi females demonstrated abundant and very active free Leishmanialike forms in an area posterior to the pylorous, between the rectal sac and the anus (posterior gut). The flagellates were not present in the midgut or Malpighi tubules. An attempt to isolate flagellate forms in NNN medium was terminated $48 \mathrm{~h}$ after inoculation due to strong bacterial contamination.

\section{DISCUSSION}

Lu. fairtigi is an endemic species from Colombia that is distributed in four of its Eastern departments (Bejarano 2007). Nothing is known about the epidemiological importance of $\mathrm{Lu}$. fairtigi, and non-natural infections with flagellate forms have been reported for this species (Young \& Duncan 1994). Our study shows for the first time the presence of flagellate forms in one $\mathrm{Lu}$. fairtigi female. If the flagellates detected in this single infected Lu. fairtigi were Leishmania parasites, the Leishmania natural infection rate for this species in the Tauramena Municipality would be of $0.3 \%$. The peripyloric location (posterior gut) of the flagellates suggests that they belong either to the genus Leishmania subgenus Viannia or genus Endotrypanum (Christensen \& Herrer 1976). Shaw (1992) distinguished infections caused by these two genera based on the abundance of flagellates in Malpighi tubules, in the case of Endotrypanum, and the absence of tubule infection, in the case of subgenus Viannia. However, Ramos et al. (1997) and Barbosa et al. (2006), discarded this criterion and, together with Christensen and Herrer (1976), highlighted individual variations in the intestinal distribution of Endotrypanum, with the greatest number of flagellates found in the midgut. Barbosa et al. (2006) found in experiments with Lutzomyia longipalpis that Endotrypanum and $L$. (V.) guyanensis differed significantly in relation to the colonization of the stomodeal valve. Williams (1999) describes both sexes of the Psychodopygus subgenus as canopy dwellers, with females also feeding in the canopy. Such behavior suggests the possibility of females being in contact with tree sloths, the vertebrate hosts of Endotrypanum (Shaw 1992). However, many Psychodopygus females have been found naturally infected with Leishmania 


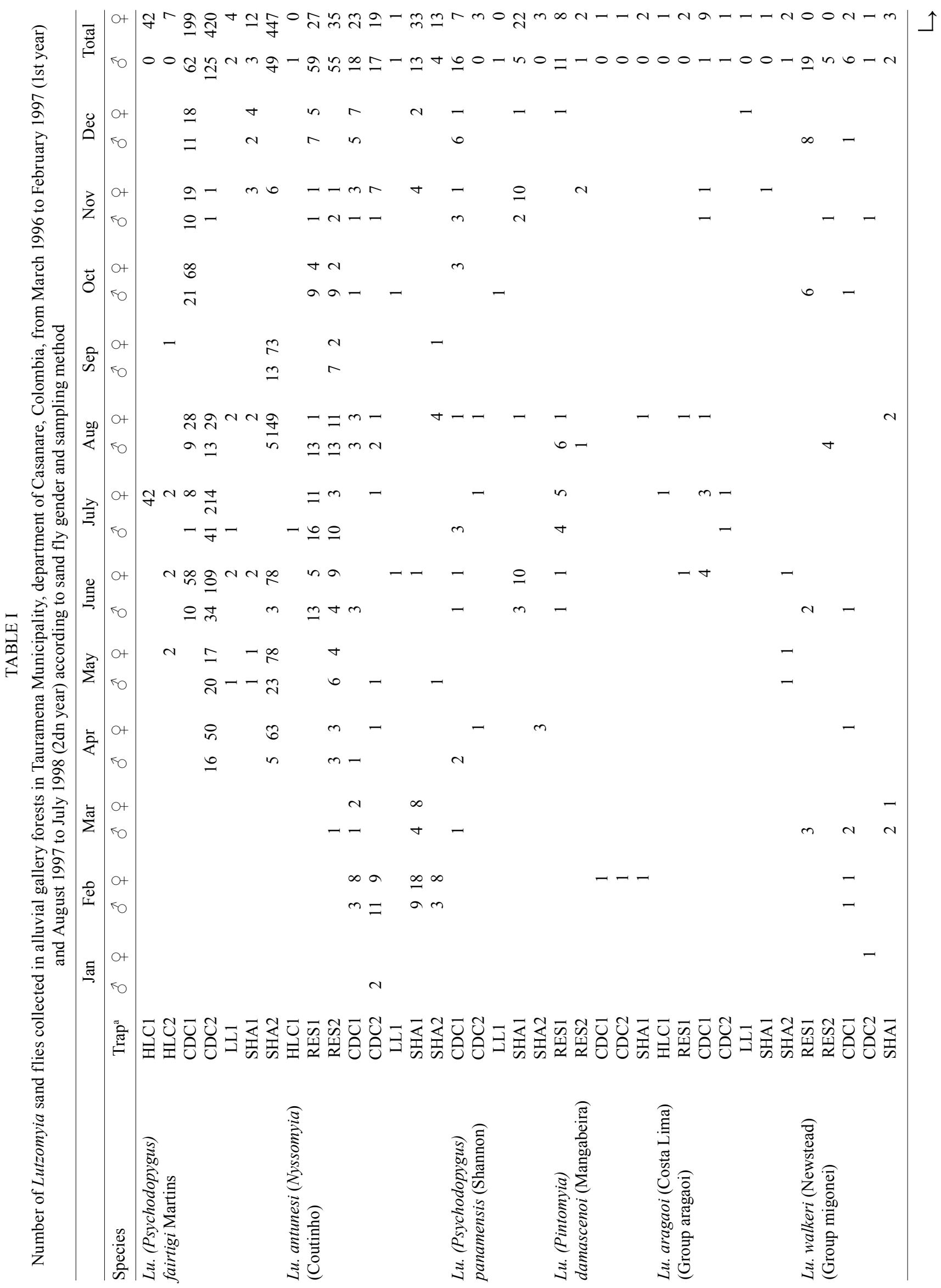




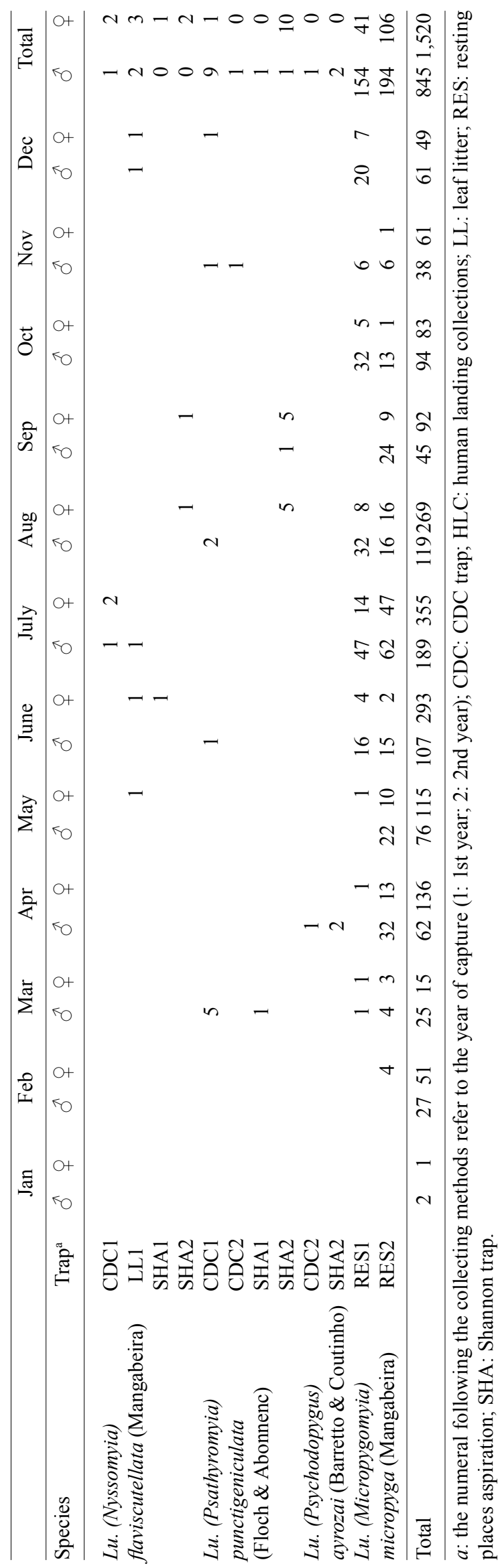

species (Williams 1999, Young \& Duncan 1994). Consequently, the presence of different flagellates in the mid and hindgut of sand flies (Johnson et al. 1963, McConnell 1963, McConnell \& Correa 1964, Wallace \& Hertig 1968) and unsuccessful attempt to isolate the flagellar forms found in one female do not answer questions associated with parasite identification and the potential vector status of Lu. fairtigi.

Among the other captured species, the following are important for their vector status: (i) $\mathrm{Lu}$. panamensis (vector of $L$. panamensis in Panama and a suspected vector in Venezuela and Honduras), and (ii) Lu. flaviscutellata (vector of L. amazonensis in Brazil, Colombia, and French Guyana, and a suspected vector in Ecuador, Surinam, Trinidad and Tobago, and Venezuela) (WHO 1990). The low anthropophilia of $\mathrm{Lu}$. flaviscutellata and its strong preference for wild rodents (Oryzomys and Proechimys) and birds (Lainson \& Shaw 1968) explains the rare transmission of Leishmania parasites to humans (Shaw \& Lainson 1968, Rodríguez et al. 1985). Primary forests, depleted secondary forests, isolated vegetation spots, gallery forests, and "varzea" are some of the ecosystems where Lu. flaviscutellata has been reported (Shaw \& Lainson 1972). However, L. amazonensis parasites were isolated from six human cases in the departments of ME and Northern Santander in Colombia (Corredor et al. 1990). The geographic distribution of these cases close to CA and the presence of Lu. flaviscutellata in Eastern Colombia (Bejarano 2007) suggest that the gallery forests in CA could be considered as an ecosystem involved in L. amazonensis transmission.

Human cases caused by other Leishmania species have been reported in CA, and include L. panamensis, L. braziliensis (Saravia et al. 1998), L. mexicana, and $L$. mexicana complex (Ovalle et al. 2006). The presence of $L u$. panamensis in this region may therefore be an important factor for the transmission of $L$. panamensis.

The different collection methods (Table I) show how species like $L u$. micropyga were exclusively captured on trees used as diurnal resting sites. This association has been related to the strong preference of Lu. micropyga to feed on cold-blooded vertebrates (WHO 1990). CDC traps captured a large number of Lu. fairtigi and $\mathrm{Lu}$. antunesi individuals (Table I), demonstrating the characteristic canopy-floor displacement of females belonging to the Psychodopygus subgenus (Williams 1999). The presence of Lu. flaviscutellata on leaf litter highlights its relationship with low-growing shrubs as a diurnal resting site (Shaw et al. 1972), as well as a site that enhances the contact of females with their food source (rodents). $\mathrm{Lu}$. fairtigi captured on leaf litter is in agreement with the observations of Chaniotis et al. (1972), who established that ground level capturing results in the collection of species with anthropophilic habits.

Diurnal and nocturnal human landing collections, the high population density in gallery forests during months of rainfall, and the presence of flagellate forms between the rectal sac and the anus of Lu. fairtigi raise the question of the epidemiological importance of this endemic species to Eastern Colombia. 
TABLE II

Correlation of climatic parameters and the three most abundant Lutzomyia sand fly species in alluvial gallery forests in Tauramena Municipality, department of Casanare, Colombia

\begin{tabular}{|c|c|c|c|c|c|c|}
\hline \multirow[b]{2}{*}{ Species } & \multicolumn{2}{|c|}{ Rainfall } & \multicolumn{2}{|c|}{ Maximum temperature } & \multicolumn{2}{|c|}{ Relative humidity } \\
\hline & $\mathrm{R}^{2}$ & $\mathrm{p}$ & $\mathrm{R}^{2}$ & $\mathrm{p}$ & $\mathrm{R}^{2}$ & $\mathrm{p}$ \\
\hline Lu. antunesi & 0.0 & 0.987 & 0.028 & 0.603 & 0.001 & 0.939 \\
\hline Lu. micropyga & 0.345 & 0.045 & 0.369 & 0.036 & 0.372 & 0.035 \\
\hline Lu. fairtigi & 0.675 & 0.001 & 0.608 & 0.003 & 0.652 & 0.002 \\
\hline
\end{tabular}

\section{ACKNOWLEDGEMENTS}

To Dr. Marta Wolff, for assistance with some literature, German Aguilera, for assistance with Fig. 1, and to referees for many detailed and helpful suggestions.

\section{REFERENCES}

Alexander B 2000. Sampling methods for phlebotomine sand flies (Diptera: Psychodidae). Med Vet Entomol 14: 109-122.

Barbosa AF, Oliveira SMP, Bertho AL, Franco AMR, Rangel EF 2006. Single and concomitant experimental infections by Endotrypanum spp. and Leishmania (Viannia) guyanensis (Kinetoplastida: Trypanosomatidae) in the Neotropical sand fly Lutzomyia longipalpis (Diptera: Psychodidae). Mem Inst Oswaldo Cruz 102: 851-856.

Bejarano EE 2007. Especies del género Lutzomyia (Diptera: Psychodidae) registradas en Colombia. Biomédica 27 (Suppl. 2): 89-92.

Chaniotis BN, Tesh RB, Correa MA, Johnson KM 1972. Diurnal resting sites of phlebotomine sand flies in a panamanian tropical forest. J Med Entomol 9: 91-98.

Christensen HA, Herrer A 1976. Neotropical sand flies (Diptera: Psychodidae), invertebrate hosts of Endotrypanum shaudinni (Kinetoplastida: Trypanosomatidae). J Med Entomol 13: 299-303.

Corredor A, Kreutzer RD, Tesh RB, Boshell J, Palau MT, Caceres E, Duque S, Pelaez D, Rodriguez G, Nichols S, Fernandez CA, Morales A, Young DG, Ferro C. 1990. Distribution and etiology of leishmaniasis in Colombia. Am J Trop Med Hyg 42: 206-214

IGAC - Instituto Geográfico Agustin Codazzi 1988. Suelos y Bosques de Colombia, Santafé de Bogotá, 135 pp.

Johnson PT, McConnell E, Hertig M 1963. Natural infections of leptomonad flagellates in panamanian Phlebotomus sandflies. Exp Parasitol 14: 107-122.

Lainson R, Shaw JJ 1968. Leishmaniasis in Brazil: I. Observations on enzootic rodent leishmaniasis-Incrimination of Lutzomyia flaviscutellata (Mangabeira) as the vector in the lower amazonian basin. Trans R Soc Trop Med Hyg 62: 385-395.

Martins AV 1970. Lutzomyia (Psychodopygus) fairtigi n.sp. from Colombia (Diptera, Psychodidae, Phlebotominae). Proc Entomol Soc Wash 72: 279.

McConnell E 1963. Leptomonads of wild-caught panamanian Phlebotomus: Culture and animal inoculation. Exp Parasitol 14: 123-128.

McConnell E, Correa M 1964. Trypanosomes and other microorganisms from Panamanian Phlebotomus sandflies. J Parasitol 50: 523-528.

Minter DM, Goedbloed E 1971. The preservation in liquid nitrogen of tsetse flies and phlebotomine sandflies naturally infected with trypanosomatid flagellates. Trans R Soc Trop Med Hyg 65: 175-181.

Ovalle CE, Porras L, Rey M, Rios M, Camargo YC 2006. Distribución geográfica de especies de Leishmania aisladas de pacientes con- sultantes al Instituto Nacional de Dermatología Federico Lleras Acosta, E.S.E., 1995-2005. Biomédica 26 (Suppl. 1): 145-151.

Ramos AM, Tesh RB, Guzman H, Deane MP, Grimaldi G 1997. Development of Endotrypanum (Kinetoplastida: Trypanosomatidae) in experimentally infected phlebotomine sand flies (Diptera:Psychodidae). J Med Entomol 34: 189-192.

Rodriguez G, Corredor A, Caceres E, Cassiano G, Arroyo C, Palau MT, Boshell J 1985. Leishmaniasis difusa. Biomédica 5: 95-111.

Saravia NG, Segura I, Holguin AF, Santrich C, Valderrama L, Ocampo C 1998. Epidemiologic, genetic, and clinical associations among phenotypically distinct populations of Leishmania (Viannia) in Colombia. Am J Trop Med Hyg 59: 86-94.

Shaw JJ 1992. Endotrypanum, a unique intraerytrocytic flagellate of New World tree sloths. An evolutionary link or an evolutionary backwater? Cienc Cult 44: 107-116.

Shaw JJ, Lainson R 1968. Leishmaniasis in Brazil: II. Observations on enzootic rodent leishmaniasis in the lower amazon region-The feeding habits of the vector, Lutzomyia flaviscutellata in reference to man, rodents and other animals. Trans $R$ Soc Trop Med Hyg 62: 396-405.

Shaw JJ, Lainson R 1972. Leishmaniasis in Brazil: VI. Observations on the seasonal variations of Lutzomyia flaviscutellata in different types of forest and its relationship to enzootic rodent leishmaniasis (Leishmania mexicana amazonensis). Trans $R$ Soc Trop Med Hyg 66: 709-717.

Shaw JJ, Lainson R, Ward RD 1972. Leishmaniasis in Brazil: VII. Further observations on the feeding habitats of Lutzomyia flaviscutellata (Mangabeira) with particular reference to its biting habits at different heights. Trans R Soc Trop Med Hyg 66: 718-723.

Wallace FG, Hertig M 1968. Ultrastructural comparison of promastigote flagellates (Leptomonads) of wild-caught Panamanian Phlebotomus. J Parasitol 54: 606-612.

WHO - World Health Organization 1990. Lucha contra las Leishmaniasis. Informe de un Comité de Expertos de la OMS. Serie de Informes Técnicos, Genebra, $170 \mathrm{pp}$.

Williams P 1999. Patterns in the geographical distribution of members of the genus Lutzomyia Franca (Diptera: Psychodidae-Phlebotominae). In JF Burger (ed.), Contributions to the knowledge of Diptera, Associated Publishers, Gainesville, p. 455-502.

Young DG, Duncan MA 1994. Guide to the identification and geographic distribution of Lutzomyia sand flies in Mexico, the West Indies, Central and South America (Diptera: Psychodidae). Mem Amer Entomol Inst 54: 1-881.

Young DG, Morales A, Kreutzer RD, Alexander JB, Corredor A, Tesh RB 1987. Isolations of Leishmania braziliensis (Kinetoplastida: Trypanosomatidae) from cryopreserved colombian sand flies (Diptera: Psychodidae). J Med Entomol 24: 587-589.

Zar JH 1999. Biostatistical analysis, 4th ed., Prentice Hall, New Jersey, $663 \mathrm{pp}$. 